\title{
Commentary: Expanding conceptualizations for the study of learning: Implications for theory and research
}

\author{
Jessica M. McKeown \& Cindy E. Hmelo-Silver
}

Indiana University, USA

\begin{abstract}
The articles in this special issue provide examples of how conceptions of studying learning need to expand to incorporate new environments and concerns in education. As technology advances the tools available to learners and instructors in synchronous and asynchronous learning environments, theory must meet the new challenges of conceptualizing these spaces and pedagogical approaches that allow for new ways of organizing learning opportunities and supporting learners. The depiction of chronotope, the ecological perspective, and social practice theory convey the need to consider new conceptualizations. Considerations of agency and emotion expand the bounds of learning in ways that are important for the educational futures that we can imagine. These exciting advances have created a need for thinking about learning in a way that reframes existing conceptualizations of how to appropriately analyze learning activities.
\end{abstract}

This collection of articles takes a stridently dynamic view of learning that goes beyond static cognition and recognizes the importance of learner agency. Some perspectives are more or less emergent in terms of their conceptions of learning and context. Although including context is not new for sociocultural theories, being specific about aspects of context is. In particular, most of these articles are concerned with the role of time and space and the relevant interactions among them. New definitions of learning must consider it as a system that looks across what might appear to be natural boundaries of time, space, and context; cognition and emotion; human and artifact: with individual agents, co-constructing groups and institutions (e.g., Engle \& Conant, 2002; Lemke, 2000). As in other systems, what emerges (i.e., what knowledge is socially constructed) is different from what might be predicted from those bounded-appearing elements.

The chronotope framework presented by Ritella, Ligorio, and Hakkarainen is a conceptual/analytical tool centered on the premise of interdependency between issues of space and time. Education research tends to treat these factors as backdrops where learning occurs instead of focusing on how they interact and present opportunities and constraints that may not occur otherwise. Here, learning is a system of complex interactions with agency at different levels, that may not always be predictable, and are defined by the timespace where the learner is situated. These lines of thinking are similar to Engle, Lam Meyer, \& Nix's (2015) ideas about how positioning learners' agency and expansively framing their ideas is a key for learning and transfer. Conceptually, Ritella et al. argue their framework could be used to design instruction while considering how space-time is used, especially in technology-rich learning environments. For example, when we consider how mobile computer-supported collaborative learning environments are used by different collaborators across different spaces and times. We echo Ritella et als. heed to consider how teachers can orchestrate learning in such complex settings. 
Similar to this study, Penuel also considers the move across settings and learner agency. Examining pathways of interest in science, technology, engineering, and mathematics fields, Penuel and colleagues adopt social practice theory, which allows for the conceptualization of structures of practice and the emergent constraints and possibilities that exist for the learner(s). Longitudinal analysis of an individual path can show us where our assumptions about education reform and programs are falling short and where they are working. This article examines how individual agency is expressed, but also attends to emergent properties of the environment/learner interaction.

Further considering agency, Damsa and Jornet discuss the study of higher education through the lens of the ecological perspective, which holds that learning is a set of dialectical relationships between the individual, others, and the environment. Learning is portrayed as a cognitive, emotional, and practical system, where the self, society, and tools necessarily impact the transformation of the others. However, each component of the system cannot be understood or analyzed without consideration of the others, as is typical of systems. Issues of co-construction and agency, knowledge resources, and trans-contextuality are highlighted in a case study of a class of computer engineering undergraduates as they interact while completing a project for a customer. The authors argue that the field of higher education study needs to consider the transformative nature of learning.

Two articles in this issue illustrate the challenges of integrating two lesser-studied aspects of cognition, imagination and emotion, into science and history respectively. Moving toward a perspective focusing on learner agency, the work detailed next highlights the dynamic and socially negotiated processes that support learner agency. The role of imagination in science education is a relatively new field of study, and as such has been lacking a framework for analysis. Building on the work of Zittoun \& Gillespie (2016) and their depiction of the distal and proximal loops of imagination, Hilppö and colleagues introduce us to the expansive and refining dynamics of imagination. They argue that these patterns of imagination allow learners to break the constraints of space and time that are often imposed by limitations of classroom settings. The expansive imagination allows shifts in meaning-making between proximal and distal times and spaces, and for pushing the boundaries of what is realistic, and possible, while refining imagination encompasses again the boundaries of reality to imagine what could happen plausibly. Benefits of tapping into imagination in science education include agency, and collective imagination, as imagination is situated and shared.

Goldberg and Schwarz take a socio-emotional approach to learning, specifically how students come to reason about historical sources. They compare three approaches to history learning on hot topics (critical inquiry, empathetic dual narrative, and patriotic apologetic teaching). These hot topics are places where emotion, identity, and agency come to the forefront, rather than creating obstacles to disciplinary discussions. The authors provided examples from four episodes, representative of different potential effects of teaching approaches on relations of emotions and history. Different teaching approaches lead to different ways that learners invoke identity and emotion — some of these approaches can support perspective taking whereas others can help make learners aware of biases and/ or impede productive engagement.

Considering multiple perspectives and biases is important for helping learners develop emotional responses that can be productive. Learning environment designs that bring out identity-related emotions can support more reflective engagement with historical thinking. It is important to consider the ways in which merging cognition and emotion can support and challenge disciplinary thinking practices. While these focus on history as a discipline, these considerations are also applicable to considering other content, such as socioscientific issues or professional education that might explicitly focus on emotionally laden content (HmeloSilver, Jung, Lajoie, Lu, Yu, Wismeman, \& Chan, 2016). In order to broaden our consideration of learning as emotionally dialogic, we need to consider the broader contextual and disciplinary spaces in which it is useful to consider this expansive perspective.

These articles were provocative in their refined conceptualizations of learning and the aspects that each article brought to the foreground. The frameworks here focused on the conceptual and analytic tools that each of the authors argued will inform education research in the 21 st century. To move this research 
forward, and taking the notion of design-based research seriously, the next step is application of these frameworks in designing for learning. This is particularly timely given the rapid changes in technology that break down many boundaries between time and space, but also require learner agency. New designs for learning must take into account a notion of learning as a systemic process with expansive boundaries; one that is dynamically unfolding, with some emergent aspects that can provide new opportunities. But with these opportunities come challenges in how to orchestrate and facilitate learning in complex environments. The designs are themselves tests of these new conceptualizations (e.g., McKenney \& Reeves, 2013). Further research into these topics needs to consider the role of the teachers, designers, and learners in dealing with the complexity of new learning spaces, as individuals influence and are also affected by components of the emergent systems in which they exist.

\section{References}

Engle, R. A., \& Conant, F. R. (2002). Guiding principles for fostering productive disciplinary engagement: Explaining an emergent argument in a community of learners classroom. Cognition and Instruction, 20, 399-484.

Engle, R. A., Lam, D. P., Meyer, X. S., \& Nix, S. E. (2012). How Does Expansive Framing Promote Transfer? Several Proposed Explanations and a Research Agenda for Investigating Them. Educational Psychologist, 47(3), 215-231. doi: 10.1080/00461520.2012.695678

Gillespie, A., \& Zittoun, T. (2016). The gift of a rock: A case study in the emergence and dissolution of meaning. Nothingness: Philosophical insights to psychology. New Brunswick, NJ: Transaction Publishers.

Hmelo-Silver, C. E., Jung, J., Lajoie, S. P., Lu, J., Yu, Y., Wiseman, J., Chan, L-K. (2016). Video as context and conduit for problem-based learning. In S. M. Bridges, S. M., L-K Chan, \& C. E. Hmelo-Silver. (Eds.), Educational technologies in medical and health sciences education (pp.57-77). New York: Springer.

Lemke, J. L. (2000). Across the scales of time: Artifacts, activities, and meanings in ecosocial systems. Mind, culture, and activity, 7(4), 273-290.

McKenney, S., \& Reeves, T. C. (2013). Conducting educational design research. Routledge.

Sandoval, W. A. (2014). Conjecture mapping: an approach to systematic educational design research. Journal of the Learning Sciences, 23, 18-36. doi: 10.1080/10508406.2013.778204 